\title{
Seizure and delayed emergence from anesthesia resulting from remote cerebellar hemorrhage after lumbar spine surgery -A case report-
}

\author{
Hyun-Young Lee, Sang-Hun Kim, and Keum-Young So \\ Department of Anesthesiology and Pain Medicine, Chosun University Medical School, Gwangju, Korea
}

A patient with remote cerebellar hemorrhage $(\mathrm{RCH})$ who was presented at the authors' hospital with seizure and delayed emergence from anesthesia after loss of cerebrospinal fluid (CSF) through a dural tear during lumbar spine surgery is described. RCH is a rare and unpredictable complication after spinal surgery. Its most common clinical features are diminished consciousness, headache, and seizure. Its mechanism is still disputed, but is probably venous bleeding secondary to significant intra- or post-operative loss of CSF. Therefore, RCH must be considered in patients with unexplained mental deterioration or disturbance upon emergence and seizure from general anesthesia after spine surgery. (Korean J Anesthesiol 2012; 63: 270-273)

Key Words: Brian hemorrhage, Delayed emergence, General anesthesia, Lumbosacral region, Seizure, Surgery.

Delayed emergence from anesthesia due to remote cerebellar hemorrhage $(\mathrm{RCH})$ after spine surgery has been published in a few reports [1]. $\mathrm{RCH}$, bleeding in the cerebellum as a complication of surgery performed at a location distant from the site of the bleeding, is a rare, unpredictable, and uncommon complication after spinal surgery [2]. Generally, patients are neurologically intact upon their emergence from anesthesia, so anesthesiologists are not likely to consider the development of RCH during spine surgery [2-4]. The mechanism of $\mathrm{RCH}$ in spine surgery remains unclear. One of its most likely causes, however, is intra- or post-operative cerebrospinal fluid (CSF) leakage from a damaged dura [5-8]. $\mathrm{RCH}$ may manifest as a headache with or without a change in consciousness that can mimic intracranial hypotension syndrome or opiate intoxication $[7,8]$. In its acute phase, the most common symptoms are nonspecific consciousness disorders such as disorientation or lethargy [9]. In this paper, a patient with $\mathrm{RCH}$ who was presented at the authors' hospital with seizure and mental deterioration after her emergence from sevoflurane anesthesia and whose dura was torn during the lumbar spinal surgery is described.

Received: September 5, 2011. Revised: October 18, 2011. Accepted: October 21, 2011.

Corresponding author: Sang-Hun Kim, M.D., Ph.D., Department of Anesthesiology and Pain Medicine, Chosun University Medical School, 588, Seasuk-dong, Dong-gu, Gwangju 501-717, Korea. Tel: 82-62-220-3223, Fax: 82-62-223-2333, E-mail: drshkim4187@yahoo.co.kr

(c) This is an open-access article distributed under the terms of the Creative Commons Attribution Non-Commercial License (http:// creativecommons.org/licenses/by-nc/3.0/), which permits unrestricted non-commercial use, distribution, and reproduction in any medium, provided the original work is properly cited. 


\section{Case Report}

This case report was approved by the institutional Ethics Committee. A 63-year-old 68-kg female was scheduled to undergo L3-4 posterior longitudinal inter-body fusion under general anesthesia. She had no history of infection, trauma, or coagulopathy, and no personal or family history of seizure or neurologic disorders, with the exception of hypertension that was well-controlled with a calcium channel blocker. Previously, she had an uneventful exposure to anesthetics for an L4-5 posterior longitudinal interbody fusion (PLIF) and a discectomy. As her premedication, she was given an intramuscular injection of $0.05 \mathrm{mg} / \mathrm{kg}$ of midazolam 1 hour prior to the induction of anesthesia. When she arrived at the operating room, her blood pressure was $125 / 70 \mathrm{mmHg}$, her heart rate was 76 beats/min, and she was well sedated with midazolam. She was given general anesthesia with $2 \mathrm{mg} / \mathrm{kg}$ of propofol and $0.9 \mathrm{mg} / \mathrm{kg}$ of rocuronium bromide, with 2 minimal alveolar concentrations (MACs) of sevoflurane and a 50\% oxygen-air mixture. She was given an injection of $1 \mathrm{mg} / \mathrm{kg}$ of lidocaine and $1 \mu \mathrm{g} / \mathrm{kg}$ of remifentanil $1 \mathrm{~min}$ before her intubation. Her hemodynamics was stable with 110/65 mmHg and 60 beats/ min during the intubation. After the induction of anesthesia, her left radial artery was cannulated to enable continuous monitoring of her arterial blood pressure. To maintain the anesthesia, the MAC of sevoflurane was controlled to keep the patient's systolic arterial pressure less than $140 \mathrm{mmHg}$ and the bispectral index within 40-60, and the carbon dioxide was kept between 30 and $40 \mathrm{mmHg}$. About $1.5 \mathrm{~h}$ after the incision, the dura was unintentionally damaged during the surgery and was sutured in a watertight manner under the CSF suction that was taken for half an hour. A total of 2,700 ml of fluid was infused with only a crystalloid, and the blood loss was minimal, at about $500 \mathrm{ml}$. The surgery took 4 hours, and a percutaneous Hemovac suction was inserted before the wound was closed. The neuromuscular blockade was reversed with $10 \mathrm{mg}$ of pyridostigmine and $0.4 \mathrm{mg}$ of glycopyrrolate. During the patient's recovery, her systolic arterial pressure was kept less than $140 \mathrm{mmHg}$ with the intermittent bolus of $1 \mathrm{mg}$ of nicardipine. Although the patient was slightly disoriented after her emergence from sevoflurane anesthesia, she responded to verbal commands and breathed spontaneously with a tidal volume of $450-480 \mathrm{ml}$ and with stable vital signs, including a BIS index of 89. Fifteen minutes after her arrival at the recovery room, she suddenly lost consciousness and did not respond to verbal commands or painful stimuli. Two episodes of generalized tonic-clonic seizures that lasted approximately 30 seconds each occurred, and were immediately extinguished with the infusion of $60 \mathrm{mg}$ of thiopental sodium and $900 \mathrm{mg}$ of sodium valporate. No abnormal laboratory values were noted

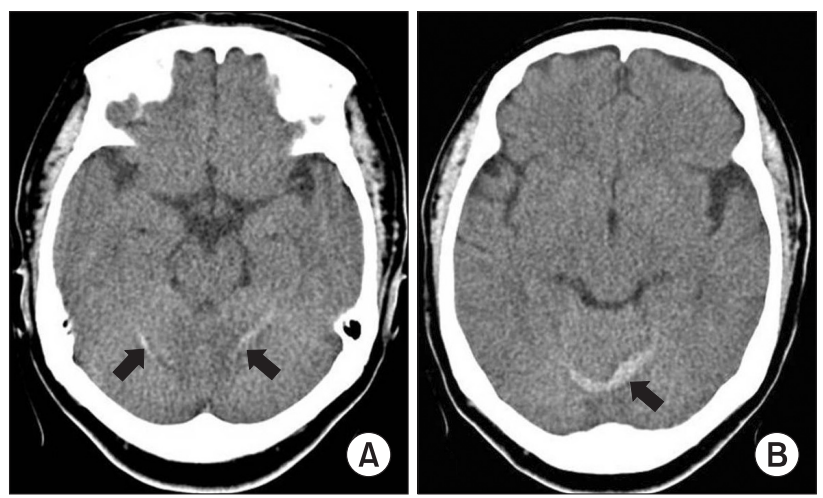

Fig. 1. Non-enhanced plain computed tomographic scan of the head $6 \mathrm{~h}$ after lumbar spine surgery revealing bilateral cerebellar hemorrhage (dark arrows).

with respect to the patient's coagulation profiles [prothrombin time $(\mathrm{PT})=13.1 \mathrm{sec}(10-14)$, activated prothrombin time $($ aPTT $)=22.3 \mathrm{sec}(28-48)$, and INR $=1.14(0.9-1.27)]$, arterial blood gas analysis, and electrolytes. A neurological consultation was conducted in the intensive care unit (ICU). The EEG examination showed seizure onset, and an urgent brain computed tomographic (CT) scan demonstrated a small amount of hemorrhage in both cerebella hemispheres 6 hours post-operatively (Fig. 1). The patient's coagulation profiles, platelet, and hemoglobin were rechecked (PT = $14.1 \mathrm{sec}$, aPTT $=21.4 \mathrm{sec}$, INR $=1.30$, hemoglobin $=11.9 \mathrm{~g} / \mathrm{dl}$, and platelet $=$ $366 \times 10^{3} / \mu \mathrm{l}$ ). A loading dose of $10 \mathrm{mg} / \mathrm{kg}$ of phenytoin was administered and maintenance phenytoin therapy $(1 \mathrm{mg} / \mathrm{kg}$ every 8 hours) was initiated based on the recommendations of the neurology consultant. The patient's level of consciousness changed to confusion with response to verbal commands and stable vital signs. The total drained volume through Hemovac was $650 \mathrm{ml}$ for 2 days, and its nature was serosanguinous. The drain was removed 2 days after the surgery. The patient recovered her normal level of consciousness in the next 5 days. She did not have further seizures, but continued to have severe headaches, which did not improve with the positional change and were only partially alleviated by analgesics. The RCH was completely resolved on the follow-up cranial CT 13 day after the surgery, and the headaches were also resolved with continuous analgesics and fluid therapy. At the time of the patient's discharge, she was neurologically asymptomatic and her headaches had completely remitted.

\section{Discussion}

Remote cerebellar hemorrhage is an unpredictable and rare complication after spine surgery and should be considered as a possible cause of unexplained post-operative neurological 
decline. Since RCH after spine surgery was first reported by Chadduck [2], reports of RCH have become more frequent in recent years. Even if its mechanisms are not exactly known yet despite the many opinions, many authors have reached a consensus that RCH occurs as a consequence of significant intra- or post-operative loss of CSF and is likely venous in origin [5-8]. One suggested mechanism is the increased transluminal venous pressure from the intracranical hypotension from CSF loss, which results in rupture of vessels [10]. Another theory is that the downward displacement of the cerebellum causes stretching and tearing of the superior vermian veins [4,11-13]. Hashidate et al. [12] suggested that the major factor of $\mathrm{RCH}$ seems to be the intracranial hypotension caused by excessive loss of CSF. Andrews and Koci [13] demonstrated that RCH is associated with reperfusion after the transient traction, kinking, or spasm of the superior cerebellar artery, and with reperfusion after the temporary traction, entanglement, or spasm of the superior cerebellar artery. There were some suggested causes such as anti-platelet therapy, coagulopathy, hypertension, and rotation of the head during surgery $[3,5,7,11,14]$. Waga et al. [14] suggested that labile hypertension and unstable blood pressure during the perisurgical period may play a role in the development of RCH. Thomas et al. [3] suggested that the position of the patient during the surgery also contributes to the development of $\mathrm{RCH}$, specifically when the patient is in the sitting position or when his head has an overextended position. The correlation of these suggested causes with RCH is controversial, though. Hashidate et al. [12] demonstrated that there is no relationship between such suggested causes and RCH. Park et al. [11] suggested that no single risk factor is totally responsible for $\mathrm{RCH}$, but that hypertension and peri-operative CSF loss seem positively correlated to it. Hashidate et al. [12] suggested that another cause of RCH is suction drainage, and that subfascial drainage without negative pressure is necessary to prevent RCH. Furthermore, they recommended immediate removal of the drainage after the detection of $\mathrm{RCH}$ to prevent the deterioration of the symptoms. Brockmann and Groden reported that the symptoms developed within 10 hours in $46 \%$ of the cerebellar hemorrhage with respect to the postoperative drainage [15]. The detection times of the neurological symptoms and RCH in previous reports were $0-72$ hours and 12-120 hours after the surgery [12]. The common clinical signs were a diminished level of consciousness and headache, and other common symptoms were motor deficits and delayed emergence from anesthesia $[1,6,8,12]$. The diminished level of consciousness may be associated with intra-operative opioid use that can mask the presence of $\mathrm{RCH}$. In the case described herein, opioid was not used to maintain the anesthesia, so opioid-induced unconsciousness could be excluded. Failure of opioid antagonists to elicit a response is an indication of an urgent brain CT scan. Brain CT or magnetic resonance imaging can facilitate the diagnosis of RCH [7]. The definite diagnostic method for dura mater tearing, one of the causes of postoperative $\mathrm{RCH}$, is scintigraphy. Although about $200 \mathrm{ml}$ of the serosanguinous fluid was drained on the day of the surgery and $450 \mathrm{ml}$ on the first day of the surgery in this case, however, the CSF leakage at the site of the repair of the dura tearing was not confirmed because scintigraphy was not performed. The RCH patient, depending on his neurological status, can be treated with surgery or conservatively. Limited RCH can be treated conservatively and followed with serial imaging, but more extensive RCH with signs of brainstem compression require immediate surgical decompression $[5,7,11]$. The risk of RCH during spinal surgery may be reduced via "head-down" positioning of the patient and immediate closure of dura when the dura is torn [4]. Furthermore, although these risks alone are not correlated with $\mathrm{RCH}$, adequate peri-operative management of blood pressure may help prevent or diminish the development of RCH after dura tearing because of its positive correlation. In this case, the major causes of the $\mathrm{RCH}$ were assumed to have been the intra-operative loss of CSF because the symptoms manifested upon the patient's emergence from anesthesia and the drained serosanguinous fluid that was suspected as CSF contributed to the deterioration of the symptoms. The amount of RCH did not deteriorate so much as to require brain surgery, perhaps partly due to the wellcontrolled blood pressure and the removal of the drainage on the first day of the surgery. In conclusion, it is important to pay attention to the surgical procedure and to be aware of $\mathrm{RCH}$ as a potential causative factor of unexplained metal deterioration or seizure of the patient upon his emergence from anesthesia after intra-operative CSF loss due to tearing of the dura during spinal surgery. Early diagnosis of this condition using a CT scan and prevention and treatment of $\mathrm{RCH}$ are also very important with respect to the patient outcome.

\section{References}

1. Nakazawa K, Yamamoto M, Murai K, Ishikawa S, Uchida T, Makita K. Delayed emergence from anesthesia resulting from cerebellar hemorrhage during cervical spine surgery. Anesth Analg 2005; 100: 1470-1.

2. Chadduck WM. Cerebellar hemorrhage complicating cervical laminectomy. Neurosurgery 1981; 9: 185-9.

3. Thomas G, Jayaram H, Cudlip S, Powell M. Supratentorial and infratentorial intraparenchymal hemorrhage secondary to intracranial CSF hypotension following spinal surgery. Spine (Phila Pa 1976) 2002; 27: E410-2.

4. Friedman JA, Ecker RD, Piepgras DG, Duke DA. Cerebellar hemorrhage after spinal surgery: report of two cases and literature review. Neurosurgery 2002; 50: 1361-3. 
5. Nam TK, Park SW, Min BK, Hwang SN. Remote cerebellar hemorrhage after lumbar spinal surgery. J Korean Neurosurg Soc 2009; 46: 501-4.

6. Farag E, Abdou A, Riad I, Borsellino SR, Schubert A. Cerebellar hemorrhage caused by cerebrospinal fluid leak after spine surgery. Anesth Analg 2005; 100: 545-6.

7. Cevik B, Kirbas I, Cakir B, Akin K, Teksam M. Remote cerebellar hemorrhage after lumbar spinal surgery. Eur J Radiol 2009; 70: 7-9.

8. Bernal-Garcia LM, Cabezudo-Artero JM, Ortega-Martinez M, Fernandez-Portales I, Ugarriza-Echebarrieta LF, Pineda-Palomo M, et al. Remote cerebellar hemorrhage after lumbar spinal fluid drainage. Report of two cases and literature review. Neurocirugia (Astur) 2008; 19: 440-5.

9. Siu TL, Chandran KN, Siu T. Cerebellar haemorrhage following supratentorial craniotomy. J Clin Neurosci 2003; 10: 378-84.

10. Toczek MT, Morrell MJ, Silverberg GA, Lowe GM. Cerebellar hemorrhage complicating temporal lobectomy. Report of four cases. J
Neurosurg 1996; 85: 718-22.

11. Park JS, Hwang JH, Park J, Hamm IS, Park YM. Remote cerebellar hemorrhage complicated after supratentorial surgery: retrospective study with review of articles. J Korean Neurosurg Soc 2009; 46: 13643.

12. Hashidate H, Kamimura M, Nakagawa H, Takahara K, Uchiyama S, Kato H. Cerebellar hemorrhage after spine surgery. J Orthop Sci 2008; 13: 150-4.

13. Andrews RT, Koci TM. Cerebellar herniation and infarction as a complication of an occult postoperative lumbar dural defect. AJNR Am J Neuroradiol 1995; 16: 1312-5.

14. Waga S, Shimosaka S, Sakakura M. Intracerebral hemorrhage remote from the site of the initial neurosurgical procedure. Neurosurgery 1983; 13: 662-5.

15. Brockmann MA, Groden C. Remote cerebellar hemorrhage: a review. Cerebellum 2006; 5: 64-8. 